\title{
Los términos de la informática y la internet en cuatro países de habla hispana: esbozo de una estrategia de divulgación ${ }^{1}$
}

\author{
The terms of computing and the Internet in four \\ Spanish-speaking countries: an sketch of an outreach \\ strategy
}

Lirian Astrid Ciro ${ }^{2}$

Resumen

Neus Vila Rubio ${ }^{3}$

El presente trabajo se focaliza en el léxico informático y, específicamente, en el relacionado con la Internet. El objetivo es realizar una descripción, desde la pragmática, de este tipo de léxico, centrándonos en la estrategia de divulgación consistente en la presentación, por parte del enunciador, del sentido de los términos. Para ello se partió de fuentes lingüísticas tomadas de la misma Internet, que representan a cada uno de los países seleccionados -Chile, Guatemala, Cuba y España- tanto desde el medio institucional (páginas universitarias) como desde el divulgativo (prensa digital).

\section{Palabras clave:}

Léxico de la Internet y la informática, divulgación de la ciencia, pragmática, lenguajes especializados, estudio léxico contrastivo.

\section{Abstract}

This essay focuses on the computing vocabulary, specifically vocabulary related to the Internet. The aim is to describe, out from the pragmatics, this vocabulary; we will focus on a strategy of popularization consisting on the presentation, from the enunciator, of the meaning of the terms. For this reason we take linguistic sources on the Internet that represent each one of the selected countries (Chile, Guatemala, Cuba and Spain) both from institutional field (university web pages) and massive media (digital press).

\section{Keywords:}

Vocabulary on Internet and computing, science popularization, pragmatics, specialized languages, contrastive lexical study.

Artículo recibido el 18 de abril de 2010 y aprobado el 28 de marzo de 2011

1 Este texto hace parte del trabajo de investigación “El léxico de la informática y la Internet en algunos países de habla hispana. Hacia una propuesta descriptiva y contrastiva" (2009), elaborado en el marco de los estudios del doctorado: "La construcción europea: sociedad, cultura, derecho y educación" de la Universidad de Lleida (España); presentado por Lirian Astrid Ciro y dirigido por la doctora Neus Vila Rubio.

2 Integrante del Grupo de Estudios Lingüísticos Regionales, Universidad de Antioquia, Facultad de Comunicaciones. Estudiante del doctorado La construcción Europea: sociedad, cultura, derecho y educación, Universidad de Lleida (España). Becaria COLCIENCIAS “Generación del Bicentenario" en la modalidad Doctorados en el exterior (convocatoria 2009). lirianastrid@ gmail.com

3 Doctora en Filología Hispánica por la Universidad de Barcelona, España. Profesora titular de Lengua Española en la Universidad de Lleida, España. 


\section{Introducción}

En el trabajo que aquí se presenta nos adentraremos en el terreno de un lenguaje especializado, el de las nuevas tecnologías de la información y la comunicación, y ello supone que el foco de nuestro análisis serán aquellas palabras que nombran los mecanismos, dispositivos, programas, aplicaciones, herramientas y demás aspectos relacionados con la informática y la red. No nos referiremos, pues, a aquella parcela de léxico, más o menos general, que los cibernautas están propagando en las sesiones de chat, en sus correos electrónicos, en foros, en comunidades virtuales, etc.

Siguiendo a Calsamiglia (1997), las fuentes que se han seleccionado para el análisis corresponden a dos canales: el institucional (estudios educativos) y los medios de comunicación (prensa, revistas, libros, televisión, radio, Internet); en el canal institucional, se tomaron páginas web de universidades de países de habla hispana ${ }^{4} \mathrm{y}$, entre los medios de comunicación, se seleccionaron algunos periódicos virtuales de estos mismos países ${ }^{5}$.

En cuanto a la selección de las fuentes desde la propia Internet, se justifica porque "los medios han tomado parte en ese discurso y, por tanto, la difusión del mismo se hace masiva. También es

4 Las universidades seleccionadas fueron las siguientes: Por Chile: Pontificia Universidad Católica de Chile http://www.uc.cl/; Universidad de Chile http://www.uchile.cl/.

Por Guatemala: Universidad Francisco Marroquín https://www.ufm. edu/index.php; Universidad Galileo http://www.galileo.edu/.

Por Cuba: Universidad de la Habana http://www.uh.cu/; Universidad de Oriente http://www.uo.edu.cu/.

Por España: Universidad de Barcelona http://www.ub.edu/homeub/ es/welcome.html; Universidad Autónoma de Madrid http://www. uam.es/; Universidad Complutense de Madrid http://www.ucm.es/; Universidad de Valencia http://www.uv.es/castellano/.

5 Estos fueron:

Por Chile: El Mercurio http://www.elmercurio.cl/; La Tercera http:// www.latercera.cl/.

Por Guatemala: El Periódico de Guatemala http://www.elperiodico. com.gt; Prensa Libre http://www.prensalibre.com.gt/.

Por Cuba: Granma http://www.granma.cu/; Nueva Prensa http:// www.nuevaprensa.com/ - La Nueva Cuba http://www.lanuevacuba. com/master.htm.

Por España: El País http://www.elpais.es; El Mundo http://www. elmundo.es; ABC http://www.abc.es; La Vanguardia http://www. vanguardia.es legítimo intentar transmitir esa inquietud a través de los mismos medios utilizados para difundir ese discurso" (Vaquero, 1997, en línea). Para el caso, el medio es la misma Internet.

Para los objetivos específicos de este trabajo, hemos centrado nuestra atención en unidades léxicas de cuatro países de habla hispana, como representantes de cuatro zonas geográficas: Chile (América del Sur), Guatemala (Centroamérica), Cuba (América insular) y España (Europa). Además del criterio geográfico, estos países son los que cuentan con el menor número de hablantes de español.

La selección de las fuentes se hizo a partir de rankings $^{6}$ mundiales, en el caso de las universidades, atendiendo a criterios de visibilidad y reconocimiento. En cuanto a los periódicos, se recurrió a páginas índices ${ }^{7}$ y se accedió a aquellos que tenían mayor número de visitas $\mathrm{y}$, al igual que en el caso anterior, una mayor visibilidad en la red.

En las páginas que siguen, se expone, en primer lugar, un apartado teórico muy concreto y simplificado de aspectos relacionados con el léxico de la informática y la Internet en español y la divulgación de la ciencia, para abordar, posteriormente, el análisis propuesto para cada uno de los países. Este partirá de la descripción de los elementos pragmáticos hallados (sólo se enunciarán ejemplos concretos de cada uno de los aspectos tomados en cuenta). Finalmente, se presentan unas conclusiones generales.

Vale la pena señalar que este trabajo es el preámbulo de una investigación que se pretende más completa y rigurosa, en la que se buscará profundizar tanto en el aspecto teórico como práctico del léxico que aquí nos ocupa. Así, consideramos esta aportación como un antecedente que sienta bases para posteriores análisis y estudios en este campo.

6 Estos fueron: Academic Ranking of Word Universities - 2007", elaborado por la Universidad Jiao Tong de Shangai, China (http:// ed.sjtu.edu.cn/rank/2007/ranking2007.htm); Laboratorio de Internet del CINDOC (CSIC) (http://www.webometrics.info/top200_latinamerica.asp); "Times Higher Education Supplement de Londres" (http:// www.timeshighereducation.co.uk/).

7 Estas fueron: http://www.prensaescrita.com/; http://periodicos.ws/; http://www.mediatico.com/es/periodicos/america\%2Dlatina/ 


\section{El léxico de la informática y la internet en el ámbito hispánico}

La teoría sobre la terminología informática en español es relativamente escasa; a esto se suma que la mayoría de quienes teorizan acerca del tema son españoles, es decir, en el ámbito hispanoamericano se reflexiona poco (o al menos con poca rigurosidad) sobre esta cuestión. Asimismo, muchos de los textos tienden a ser reiterativos en algunas apreciaciones y muy pocos parten de corpus o ejemplos concretos; eso sí, proliferan glosarios sobre estos términos. En consecuencia, hemos acudido, para fundamentar nuestro trabajo, a aportaciones específicas que han tratado con mayor rigor los rasgos distintivos del léxico de la Internet y la informática en español, aplicándose a casos concretos. Adviértase que en esta perspectiva sólo se encontraron, en una primera búsqueda, dos trabajos: una tesis doctoral de la Universidad de Alicante (España), Estudio morfológico contrastivo Inglés-español sobre terminología de la informática y de Internet, elaborada por José Ramón Belda Medina (2000), y una tesis de licenciatura, ESPAN-L, un "foro de debate" en la internet sobre la lengua española, de la Universitat de Barcelona (España), elaborada por Mar Cruz Piñol (1999).

Según esto, es posible considerar que el léxico de la informática presenta ciertos problemas; el primero de ellos es que su presencia en los diccionarios generales y específicos es muy restringida, puesto que se ocupan más de asuntos relacionados con las ciencias exactas y naturales. Sin embargo, podría argüirse que abundan catálogos léxicos en Internet -lo cual es cierto-, pero éstos no son rigurosos y en su mayoría sólo muestran equivalencias entre términos españoles e ingleses. Así lo enuncia Belda en su tesis doctoral:

El volumen de investigación sobre terminología informática en nuestro país [España] ha crecido en los últimos años. No obstante, muchos de ellos son diccionarios y glosarios inglés-español, que hacen acopio de un ingente número de términos. Pero muchos de estos trabajos se convierten con frecuencia en simples listas bilingües de términos informáticos que quedan pronto desfasadas ante la aparición de nuevos glosarios. Sin embargo, son pocas las obras que se han dedicado a estudiar minuciosamente los recursos lexicogenésicos de nuestro idioma y la morfosintaxis española propia de la terminología informática ${ }^{8}(2000$, p. 12, en línea).

Otro aspecto a resaltar es que gran parte de la teoría sobre la terminología informática se encuentra en Internet; pero, lamentablemente, un número notable de tales referencias llevan a "enlaces muertos".

Hechas las generalidades anteriores, en primera instancia nos apropiamos de unos antecedentes algo más reflexivos, que nos permiten sentar las bases para la realización de un trabajo de esta índole.

Partimos del texto La terminología informática en español, de Gloria Clavería, Carmen Morales y Joan Torruella (2001). A propósito, señalan que el léxico es un aspecto esencial de las lenguas de especialidad; quizá -continúan- es el elemento más importante. Asumen, igualmente, que otras particularidades lingüísticas de este tipo de lenguaje son la preponderancia del medio escrito y algunos rasgos estilísticos y morfosintácticos, en virtud de lo cual estas lenguas deben ser concebidas como plurisistemas.

Adicional a lo anterior, Clavería, Morales y Torruella resaltan como característica, entre otras, de la terminología informática en lengua española "la dependencia del inglés, puesto que es en esta lengua en la que se acuñan por primera vez los términos que designan los conceptos de esta actividad específica" (2001, en línea).

Dentro de este marco, es de significativa importancia la revisión de la tesis ESPAN-L, un "foro de debate" en la Internet sobre la lengua española. La misma cuenta con un capítulo muy interesante, "El léxico del español de la Internet", y con suficientes ilustraciones sobre las características del léxico de la informática. Cada uno de los aspectos lingüísticos que se tratan están, de un lado, ampliamente ejemplificados; de otro, con sustentos teóricos consistentes. Cabe agregar, como la misma autora señala, que este capítulo no representa la parte central de

8 Han corrido nueve años desde la elaboración de la tesis de este autor y la situación no ha cambiado de manera sustancial. 
su tesis; en contraste, permite evidenciar nuevas perspectivas de análisis, las cuales será interesante retomar luego. A lo dicho, agrega que este capítulo en particular "es el anuncio del interés lexicológico que presenta el español de la Internet, un nuevo lenguaje técnico que está produciendo nuevos términos para denominar nuevas realidades, cada vez más presentes en la vida cotidiana” (Cruz Piñol, 1999, en línea). A tenor de lo dicho, la autora asevera que es muy reconfortante saber de este vivo interés en el mundo de habla hispana por estudiar el español "en y para la Internet".

Finalmente, podemos decir que estos textos brindan elementos importantes en la búsqueda de antecedentes que soporten este ejercicio académico. No obstante, se quedan en el caso de España, asunto que confirma la necesidad de abogar por estudios que planteen un panorama general de la terminología informática en español, tomando como base todos los países de habla hispana. Así, y en coherencia con lo planteado, este trabajo pretende contribuir a ello.

\section{Consideraciones pragmáticas: la divulgación de la ciencia}

Según Gutiérrez (2005), el lenguaje científicotécnico es un subsistema lingüístico, por tanto, hace parte de la lengua general ${ }^{9}$. No obstante lo planteado, posee unas características diferenciadoras que no atienden al aspecto gramatical, pues en éste la lengua de especialidad se nutre de las reglas de la general. En esta línea, la principal diferencia radica en el aspecto léxico, el cual exige ciertos niveles de comprensión; así, se afirma que este tipo de lenguaje no está dirigido a cualquier tipo de receptor, puesto que en los lenguajes específicos el léxico especializado no se puede sustituir; por ello, en este campo la sinonimia puede aparecer inconveniente.

En coherencia con lo expuesto, está la teoría general de la terminología que parte de los presupuestos de Wüster. En sus postulados reza que los términos no poseen un valor pragmático; tampoco

9 Entendida como sistema lingüístico macro, lo que implica que debe ser comprendida en un sentido amplio, esto es, que no se limita al léxico común, sino que es pertinente a todos los registros y ámbitos de conocimiento. presentan variación semántica en virtud de que se ubican exclusivamente dentro de un registro; empero, éstos "son unidades recursivas y dinámicas que pueden 'pasar' de un campo de especialidad a otro. Esta capacidad explica la movilidad de las unidades del léxico común hacia el léxico especializado, e incluso su movilidad de una especialidad a otra" (Cabré, 2002, en línea), lo cual lleva a pensar que el estudio del aspecto pragmático puede arrojar datos interesantes sobre las lenguas de especialidad, sobre todo en el ámbito de la Internet y la informática.

En esta misma dirección, surgen los planteamientos de Calsamiglia, para quien existe una clara diferencia entre el lenguaje de especialidad y el general, lo que lleva a que se presente una dificultad para la transmisión de conceptos científicos a un público no especializado. Así lo hace saber:

\footnotetext{
La ciencia se representa discursivamente a través de tecnolectos con una proporción muy elevada de terminología, que corresponde a una elaboración conceptual extremadamente precisa y fijada. Un término denomina unívocamente -con escasa variación sinonímica- a un determinado concepto, el cual queda definido a partir de sus relaciones con otros conceptos con los que conforma una amplia red semántica, previamente elaborada y definida (2001, en línea).
}

De lo anterior se deduce que centrar la atención en el aspecto pragmático, en el tipo de trabajo que pretendemos, implica partir de un concepto básico: la divulgación de la ciencia, por cuanto nos lleva a deliberar en torno de la importancia de la relación que se establece entre el divulgador y el público no especialista en alguna materia, en este caso, en el campo informático.

Respecto a esto, es preciso indicar que la divulgación de las lenguas de especialidad se puede dar en diversos tipos de textos escritos, tanto por especialistas como por quienes no lo son. Esto propicia que los emisores y los receptores de los mismos puedan ser:

a. Especialista-especialista.

b. Especialista-público general.

c. No especialista (divulgador)-público general. 
En el corpus que aquí analizamos, en el caso de la prensa digital dicha relación se ubica entre divulgador y público no especializado; también nos encontramos con casos del segundo tipo (especialista-público general) en los artículos de las revistas universitarias, lo que permite establecer un paralelo entre estos usos.

En el próximo apartado presentaremos una estrategia de divulgación consistente en enunciar diversos mecanismos empleados por el enunciador para dar a conocer el sentido de los términos; aquí se puede evidenciar la estrecha conexión entre elementos semánticos y pragmáticos, pues al existir una intención definicional ya se entrevé el tipo de relación que se establece entre emisor y receptor y la intencionalidad del primero.

\section{Estrategia de divulgación: presentación del sentido de los términos}

En términos generales, en los países seleccionados, los artículos de la prensa digital consultada son muy breves ${ }^{10} \mathrm{y}$ no dan mayor información sobre las palabras. Así, se evidencia que este tipo de léxico, a pesar de referirse sólo a una dimensión -la Internet- se asume como un léxico compartido; por ello es difícil determinar las barreras entre el léxico especializado y el cotidiano, aunque queda claro que están dirigidos a un público general, es decir, tienen, en cierto modo, un carácter divulgativo.

De otro lado, para Calsamiglia,

la función comunicativa del texto no es solamente referencial, sino que se abre a otras funciones como la metalingüística, la expresiva, la conativa, y especialmente la poética, porque a través de recursos expresivos como la comparación, la metáfora y la metonimia se concreta aquella vieja manera de comprender lo que es lejano y abstracto con lo que es más cercano y conocido. En resumen: la nueva relación interpersonal y el encuentro entre dos universos de referencia distintos justifican las posibilidades abiertas del registro divulgativo (1997, en línea).

10 Debido, sobre todo, a las características del soporte.
Lo expresado en esta cita prácticamente no sucede en el corpus que se presenta, pues los textos son más directos. De ahí que exista la duda de si los redactores buscaban realmente la divulgación de la ciencia o más bien la comercialización de un producto.

En la prensa digital consultada, en algunos ejemplos que enunciaremos más adelante, queda claro que la función predominante es la referencial, los textos presentan algunos términos específicos y tienen como características la "claridad, economía y precisión”, en lo que se refiere a la intención del enunciador, que es informar. De acuerdo con lo anterior, queda en entredicho que haya una verdadera divulgación científica. Finalmente, el medio de trasmisión, la Internet, podría justificar, como ya lo dijimos, la brevedad de los textos y el tipo de estrategias discursivas empleadas.

Aclaramos que hemos incluido las funciones del lenguaje en el aspecto pragmático, sobre todo, porque a partir de ellas se puede evidenciar cómo el emisor vislumbra a sus posibles receptores y cómo "manipula" la información para transmitir su mensaje. Nos hemos focalizado en las funciones metalingüística y referencial, pues éstas son las que más se presentan en el corpus recolectado.

Desde otra óptica, Giovanna Mapelli, al realizar un recuento de una investigación sobre La difusión de la terminología en la prensa, indica que en este medio "a veces, se explica el tecnicismo haciendo referencia a su función (definición que se apoya en la finalidad del objeto) o, en menor medida, a su composición (forma de definición que analiza los componentes) [...]" (2003, en línea). Aunque esta investigación parte de la prensa española, la afirmación de la autora se aplica perfectamente al resto de países seleccionados, donde el qué es parece ser lo menos importante, tal como se puede observar en el corpus que en este trabajo se presenta.

Otro de los recursos empleados por los redactores en los ejemplos hallados de términos de la informática y la Internet se enlaza con "aposiciones explicativas", según lo identifica Mapelli (2003, en línea). Aquí la paráfrasis y el vocablo específico "se yuxtaponen y están separados por una coma o un 
paréntesis. El divulgador quiere precisar aspectos significativos de los elementos conceptuales mediante una aclaración discursiva [...]" (2003, en línea). De ello tenemos varios ejemplos ${ }^{11}$ no sólo en la prensa digital, sino también en las revistas y las tesis doctorales ${ }^{12}$ consultadas.

De igual modo, Mapelli indica que en la gran mayoría de los artículos de revistas especializadas "muchos términos quedan sin explicación ya que se supone que el lector tiene un acervo cultural suficiente como para entender tales conceptos" (2003, en línea). Eso parecen intuir los redactores en el ámbito de la informática y la Internet de la prensa digital de los países seleccionados, quienes, según se infiere en los ejemplos que presentaremos, escriben para un público familiarizado con el tipo de léxico que exponen en sus textos y que por esta razón no pretenden mayores especificaciones al respecto. Paradójicamente, en las revistas universitarias y en las tesis, que supuestamente van dirigidas a un público un poco más especializado, sí se brinda diversa información en relación con algunos términos.

Asimismo, caracteriza los artículos de divulgación en la "prensa ordinaria", de la siguiente manera:

Donde quien escribe es un periodista y no un científico, la noticia es bastante breve y lo que se comunica aquí es sólo una parte del quehacer científico, aquella parte que responde a las preguntas y a las necesidades prácticas del hombre. En este último caso, sobre todo, el divulgador intenta imaginar el perfil de su interlocutor y el conjunto de sus intereses y curiosidades, actuando como una especie de mediador entre las dos culturas. Y es por esta razón que, en el cuerpo de la noticia, se da espacio a la dimensión social y ética de los problemas derivados del desarrollo de la ciencia, más que al progreso científico en sí (Mapelli, 2003, en línea).

Lo primero -la poca extensión de los artículos y la imagen del redactor sobre sus posibles lectores-

11 Los que serán enunciados luego.

12 Tanto las revistas como las tesis doctorales son tomadas de las páginas universitarias seleccionadas. se da en el corpus recolectado, pero lo otro no se vislumbra.

También se dan, en mayor o menor medida, algunos de estos elementos en el corpus que aquí se presenta, según lo anuncia García:

De la misma manera que optará por estructuras sintácticas transparentes, identificables por ser habituales en la lengua común, el léxico que seleccione será el propio de esos intercambios comunicativos, aunque se verá obligado en algunas ocasiones a utilizar términos de la especialidad, pero siempre en una proporción reducida. Cuando lo haga, no obstante, consciente de la dificultad de comprensión para el destinatario, se preocupará de acompañar al término con una definición aclaratoria o con una comparación que permitan entender, aunque no sea con toda la precisión inherente al término en el ámbito especializado, el contenido del elemento léxico utilizado. En otras ocasiones utilizará metáforas que resultan mucho más transparentes que el término en cuestión, al que difícilmente ve una motivación el hablante común (2001, en línea).

Acerca de las metáforas, tema ya señalado por otros autores, es una estrategia discursiva poco empleada en los textos de las fuentes consultadas, como también es poco frecuente lo que propone este autor, pues en la mayoría de los ejemplos que veremos más adelante, la función predominante sigue siendo la referencial y, en menor medida, la metalingüística:

A la función referencial, dominante en los textos especializados, destinados fundamentalmente al intercambio de información, se añaden en los textos divulgativos otras funciones secundarias con el fin de conseguir esa mejor comprensibilidad, añadir la necesaria dosis de entretenimiento, o persuadir sobre la importancia del hecho que se está comunicando. No es de extrañar por tanto que en el texto producido veamos implicado al emisor o que al analizarlo comprobemos que los textos divulgativos se caracterizan por la hibridación que en ellos se produce desde el punto de vista de las funciones comunicativas y de la tipología textual (García, 2001, en línea). 
Con todo lo expuesto hasta aquí, respecto de las fuentes, podemos indicar que una diferencia clave entre ambas es que, en su mayoría, los periódicos digitales no brindan "pistas" sobre el sentido de los términos, aspecto que sí se presenta en los artículos de las revistas y demás textos de las universidades. Son contados los ejemplos en el corpus de la prensa digital donde se dan indicios para identificar el sentido del término, y cuando esto ocurre, éstos son poco explícitos. En otros casos, muchos de ellos, se da por hecho que los posibles receptores conocen el sentido de dichos términos. Por el contrario, en las revistas digitales y en otros textos (por ejemplo, tesis) de universidades sí es evidente la función metalingüística, pues se tiende a dar una explicación de los términos a los lectores.

En algunos casos se brinda una información indirecta; en la misma predomina el uso de los hiperónimos, por los que se infiere el sentido del término o al menos su utilidad, tal como podemos observar en los siguientes ejemplos ${ }^{13}$ :

- También hemos sido testigos de la proliferación de algunos medios de comunicación como Internet que poco a poco ha ganando terreno y popularidad frente a otros medios tradicionales. (El éxito de los medios y la publicidad digital responden a un gran "cambio generacional", e-comercio, Universidad de Oriente, sin autor, sin fecha). [Fuente cubana (FC)]

- Según cifras publicadas por el FBI, el 84 por ciento de las empresas estadounidenses fueron atacadas por virus, $\boldsymbol{s} \boldsymbol{p} \boldsymbol{y}$-ware $\mathrm{y}$ otros programas malignos durante 2005. (Revista D, Semanario de Prensa Libre, 20 años de virus informáticos, 2006, No 124). [Fuente guatemalteca (FG)]

- Internet es la nueva y futura forma de acceso al conocimiento. Sus páginas se han convertido en un valioso escenario para la obtención y presentación de trabajos sobre las más diversas temáticas del saber. Además, con los servicios y herramientas adicionales de esta tecnología (Chat, e-mail, IRC, foros, etc.), se pueden con-

13 En negrita se presenta el término y se subraya el hiperónimo. vocar además a la discusión e intercambio de conocimientos relacionados con los trabajos de difusión e investigación que ellos proponen. (Bello, Revista Alma Máter, El fin de las distancias, 8 de enero del 2009). [FC]

En algunos ejemplos la información adicional que se entrega es más una sinonimia y se introduce por la conjunción disyuntiva 'o'. Dicha sinonimia se establece, generalmente, entre el término en español y su versión en inglés:

- Ello se demuestra al cruzar la información sobre el aumento de comentarios o posts en los últimos años con las fechas en que han ocurrido acontecimientos de relevancia mundial [...] en los cuales se aprecia un importante aumento sobre el promedio de artículos nuevos diarios, que actualmente equivale a 1,6 millones... (Morales, Revista Comunicación y Medios, 2006, No 17). [Fuente chilena (FCH)]

- En este estadio proliferan las populares bitácoras o blogs, el podcast (transmisión de audio en línea) y los $v$ logs (blogs de videos), y emergen conceptos como el llamado periodismo participativo y la publicación colaborativa... (Morales, Revista Comunicación y Medios, 2006, No 17). [FCH]

- Por su parte Bartolomé Pina (1996) considera que la investigación en medios es uno de los más frecuentes temas de estudio y agrupa los estudios de acuerdo con tres perspectivas: Hardware o equipos, Software o programas $y$ Coursware o procesos educativos. (Peirats Chacón, José. Variantes organizativas generadas por las tecnologías de la información. Un estudio en los centros de primaria de la comunidad valenciana. Valencia, 2007. Tesis doctoral). [Fuente española (FE)]

- En cuanto al material en línea u on-line, destacan la actualización, la densidad y la recuperabilidad como puntos fuertes. (Fernández. El uso beneficioso del libro impreso y del libro digital. Documentación de las Ciencias de la Información, 2007, vol. 30). [FE] 
En otros casos, el intento de definición por parte del redactor es muy explícito; en algunos de ellos se emplean paréntesis para hacer una aclaración sobre el sentido del término; seguidamente, algunos ejemplos:

- Si quieres asegurarte de que todo lo anterior está bien configurado, puedes enviar un mensaje a tu propio buzón de Internet. A los pocos segundos recibirás el mensaje; contéstalo por el procedimiento de respuesta automática $(\underline{r e p l y)}$ y verifica que esta respuesta también la recibes correctamente... (Universidad Autónoma de Madrid, Netiqueta, sin autor, sin fecha). [FE]

-...nos referimos fundamentalmente a tres grandes sistemas de comunicación: el vídeo, la informática y la telecomunicación. Y no sólo a los equipos (hardware) que hacen posible esta comunicación, sino también al desarrollo de aplicaciones (software)... (Peirats Chacón, José. Variantes organizativas generadas por las tecnologías de la información. Un estudio en los centros de primaria de la comunidad valenciana. Valencia, 2007. Tesis doctoral). [FE]

Por otra parte, en las revistas universitarias o de otras fuentes académicas, como las tesis doctorales, los autores son más explícitos y presentan suficiente información respecto del término. Veamos:

Cerezo Grau (2002) explica que el XML es un metalenguaje mediante el que los desarrolladores pueden crear sus propios elementos para satisfacer sus propias necesidades de información. XML se emplea para crear metavocabularios adaptados a las necesidades de cada industria o disciplina. Un documento XML contiene sólo datos y etiquetas. Su objetivo es separar contenido de presentación, lo que permite una gran flexibilidad en el procesamiento y visualización. La estructuración de datos usando XML permite acceder a ellos a través de múltiples plataformas y aplicaciones, realizar búsquedas eficientes y utilizar diferentes hojas de estilo para la visualización de los datos en distintos formatos. (Castillo Blasco, Lourdes. Elaboración de un tesauro de información de actualidad y conversión en red semántica para su empleo en un sistema de recuperación periodístico. Valencia, 2006. Tesis doctoral). [FE]

Hay una excepción con una fuente guatemalteca; aunque es una revista, no pertenece a una universidad, sino a un periódico: la Revista D del periódico Prensa Libre. En ella prevalece la función metalingüística. Para la muestra, un ejemplo:

El libro, TICs en las PYMES de Centroamérica, define a estas como los medios e instrumentos que se emplean para hacer posible la transmisión de la voz, datos, vídeos e imágenes en forma digital. Es decir, aquellos medios digitales que permiten comunicarnos, así como tener acceso, crear y procesar todo tipo de información en tiempo real. Entre estos están, la Internet y todo lo que genera, teléfonos, computadoras, programas de software y la televisión. (Martínez, Revista D, Semanario de Prensa Libre, Separados por un clic, 2006, $\mathrm{N}^{\circ}$ 108). [FG]

En lo anterior se evidencia que los artículos de las revistas se preocupan más por divulgar estos términos, mientras que en los periódicos lo relevante es informar, sin profundizar en el sentido de éstos.

A continuación, haremos algunas anotaciones referidas a los países. Iniciaremos con Cuba, pues es uno de los que presenta mayores divergencias, ya que en la mayoría de los ejemplos no hay una intención de definición, lo cual supone que se considera que el receptor conoce el sentido del léxico informático empleado. En contraste, también hay ejemplos desde los cuales se puede deducir el sentido de los términos o donde estos se definen explícitamente. Esto último es frecuente, sobre todo, en el periódico La Nueva Cuba. En cuanto a las fuentes universitarias, esto no es tan evidente.

Cuba se diferencia de las otras fuentes porque en algunos periódicos predomina una valoración del término desde la ideología. Aquí podemos observar lo que Cassany y Martí denominan 'modalización'. Consiste, como su nombre indica, en "modalizar el discurso con elementos altamente subjetivos (juicios de valor, opiniones, apreciaciones, etc.) que delatan el punto de vista del periodista sobre su enunciación y que, además, acercan el discurso a su público [...]" (1998, en línea). Esta estrategia "salta a la vista" en 
la prensa cubana, tal como se puede apreciar en los siguientes ejemplos donde predomina un punto de vista subjetivo:

- Internet es la mercancía insigne del neoliberalismo, cuando en realidad debe estar totalmente al servicio de los pueblos y no de las transnacionales y sus intereses (Schlachter, Paradojas en Internet, Granma, 15 de noviembre de 2006). [FC]

- En ese contexto ambivalente la mayor y más profunda paradoja de Internet es su utilización como arma política de los pueblos contra el mismo imperio, que ha comercializado y privatizado a escala mundial el sistema basado en el uso electrónico del ciberespacio. (Schlachter, Paradojas en Internet, Granma, 15 de noviembre de 2006). [FC]

- A pesar del bloqueo constante de acceso a la Internet, la burla a la ciudadanía que resultan las Intranets (o redes filtradas y controladas de acceso a un Internet de mentiritas) y de la imposibilidad del ciudadano cubano común y corriente de tener libre acceso a la red informática y participar libremente en el intercambio mundial de ideas e información, miles de cubanos logran clandestinamente viajar a la internet... (Sánchez, La Nueva Cuba, 10 de junio de 2006). [FC]

En el caso de España sigue predominando, sobre todo en la prensa digital, la ausencia de explicaciones sobre un término. En los artículos de las revistas universitarias y en las tesis doctorales se tiende a dar estas explicaciones a pie de página, algunas veces de forma muy detallada, tal como se puede apreciar en este ejemplo:

Dentro del movimiento de la cibercultura[1] existen diversos tipos de protagonistas conocidos generalmente como ciber-rebeldes, que defienden y promueven la libertad de uso y acceso a la información en distintos grados y niveles. Uno de estos actores es particularmente el hacker[2], quien con sus habilidades computacionales hace posible la creación y propagación del movimiento de software libre a nivel mundial. (Torres y Zurita.
Software libre y libre acceso a la información: ¿Hacia un ciberespacio público? Documentación de las Ciencias de la Información, 2007, vol. 30). [[1] Definición a pie de página: "El término cibercultura se refiere, principalmente al impacto social derivado de las nuevas tecnologías vistas desde dos áreas: inteligencia artificial (computación y ciencias de la información) y biotecnología (porque conecta nuestros sentidos a la realidad virtual $o$ al ambiente artificial creado por ordenador, como mecanismo protésico de órganos o sistemas fisiológicos humanos."] [[2] Definición a pie de página: "Los hackers ... son, simplemente, personas con conocimientos técnicos informáticos cuya pasión es inventar programas y desarrollar formas nuevas de procesamiento de información y comunicación electrónica"]. (Torres y Zurita. Software libre y libre acceso a la información: ¿Hacia un ciberespacio público? Documentación de las Ciencias de la Información, 2007, vol. 30). [FE]

También se presentan casos semejantes en otras fuentes, como la cubana:

Los debates pueden ser de programación en $\mathrm{C}++$, o sobre el personaje más gustado de la saga El señor de los anillos, pero en todos se transmiten matrices que contribuyen al enriquecimiento cultural y cognoscitivo de los participantes. (Medina, Revista Alma Máter, Universidad de la Habana, Comunidades virtuales en la UCI. Inter-cambiar en la Red, 3 de septiembre de 2007) [Definición a pie de página: Lenguaje de programación que abarca la programación estructurada, genérica y orientada a objetos]. [FC]

Como se observa, esto sólo acontece en las páginas universitarias.

De otro lado, en Guatemala los dos tipos de medios consultados presentan unas muestras muy homogéneas, sin diferencias, o al menos sin que valga la pena resaltarlas; es más, en ambos medios predomina un discurso informativo en el cual, en la mayoría de los casos, los términos se quedan sin definir. Nos atrevemos a aseverar que dan por sentado que el receptor ya los conoce; por tanto, no requiere mayores especificaciones al respecto. 
Algunos aspectos que podemos generalizar son:

a. En relación con la estrategia divulgativa de presentación del sentido de un término, gran parte de los redactores se enfocan más en el uso de un determinado dispositivo o programa, generalmente, tratando de ejemplificar.

b. También se encuentran definiciones más o menos precisas, pero en algunos casos siguen faltando datos.

c. Finalmente, hay casos muy interesantes, en donde claramente se materializa la función metalingüística, pues se brinda suficiente información acerca del término en cuestión.

En el caso particular de Guatemala y de Cuba, y de acuerdo con la selección de las fuentes en estos países, es indudable que en las universidades el aspecto tecnológico no es tan fuerte o al menos no se cuenta con un órgano de difusión sólido, aspecto que sí es un tanto más revelador, valga la salvedad, en el periódico Prensa Libre de Guatemala. De acuerdo con lo anterior, es posible concluir que el aspecto divulgativo está más a cargo de la prensa que del medio institucional; algo un poco diferente se puede afirmar de los otros dos países.

A continuación, se presentan algunos ejemplos concretos de lo enunciado. En negrita aparece el término y se subraya la información adicional que se brinda al respecto.

En primer lugar, la definición de los términos como estrategia de divulgación, en la mayoría de los países, como ya lo hemos enunciado, se presenta en revistas y en tesis doctorales:

- La WWW es una red flexible de redes dentro de Internet donde las instituciones, las empresas, las asociaciones y los individuos pueden crear sus propios "lugares" $y$, en virtud de ellos, cualquiera con acceso puede producir su "página particular", compuesta por una mezcla variable de texto, imágenes y sonido. (Peirats Chacón, José. Variantes organizativas generadas por las tecnologías de la información. Un estudio en los centros de primaria de la comunidad valenciana. Valencia, 2007. Tesis doctoral). [FE]

- "El primer registro te obliga a pagar dos años en vez de uno para desanimar a los ciberocupadores", señala Furlán en referencia a las personas que se dedican a comprar nombres de domino con marcas o entidades conocidas a fin de revenderlas y obtener un beneficio económico. (Redacción Revista D, Revista D, Semanario de Prensa Libre, El dominio .gt, 2007, $\mathrm{N}^{\circ}$ 175). [FG]

- El estudio WIP analizó tres tipos de contenidos publicados por los internautas en la red: páginas web personales, blogs (publicación de opiniones a través de una especie de diario de vida donde el autor relata actividades realizada o expresa su opinión sobre temas de su interés) y fotologs (blogs o galerías de fotos propias que el autor actualiza periódicamente). (Godoy, Cuadernos de Información, No 20, 2007 - I). [FCH]

- En el medio digital, y potenciado por el desarrollo de las Nuevas Tecnologías de la Información y la Comunicación (NTIC) han comenzado a aflorar las comunidades virtuales, entendidas como agregaciones de individuos que encuentran en el ciberespacio la posibilidad de interactuar, movidos por inclinaciones en común. Uno de los principales investigadores del fenómeno, Howard Rheingold, las ha definido como «agrupaciones sociales que emergen de la Red cuando suficientes personas sostienen discusiones públicas de gran duración con suficiente sentimiento humano como para formar webs de relaciones personales en el ciberespacio». (Medina, Revista Alma Máter, Universidad de la Habana, Comunidades virtuales en la UCI. Inter-cambiar en la Red, 3 de septiembre de 2007). [FC]

Asimismo, se observa que en algunos países predominan unos procedimientos sobre otros; veamos: en Chile el procedimiento que más se usa es la sinonimia introducida por la conjunción 'o': 
- Lo que ofrecen, en cambio, los blogs o las páginas personales, hechas a veces por periodistas pero generalmente producidos por alguien que da referencias muy escuetas acerca de su profesión, capacitación o adhesión ideológica o religiosa, es puro misterio. (Santibánez, Revista Comunicación y Medios, 2006, № 17). [FCH]

- Catalogado como el concepto más popular en Internet hoy en día, la bitácora personal en línea, weblog, o, simplemente, $\boldsymbol{b l o g}_{2}$ es por definición una publicación individual o grupal de la web en las que, de manera cronológica, pero sin periodicidad establecida, el autor o los autores publican comentarios, notas o artículos. (Morales, Revista Comunicación y Medios, 2006, No 17). [FCH]

- En ese contexto, la fórmula utilizada por los wikis o sistemas de redacción colaborativa surgen como una interesante respuesta, ya que funcionan sobre la base del concepto de "inteligencia repartida" en la cual la suma de los conocimientos de muchos usuarios en la red es más edificante que el de una sola persona. (Morales, Revista Comunicación y Medios, 2006, No 17). [FCH]

En Cuba, el procedimiento que sobresale es el de información indirecta (implícita):

- Gracias a la Internet, es posible establecer comunicación directa e inmediata desde lugares muy distantes del planeta, buscar, recibir y enviar información e incluso mediante las webcam es posible ver y oír la persona con quien nos estamos comunicando. (Cruz, Revista Alma Máter, Universidad de la Habana, Informática: amiga o enemiga del idioma español, 27 de abril de 2007). [FC]

- Según cifras oficiales, unos 900 mil cubanos tienen acceso a internet, contando universidades, cuarteles, asociaciones, hoteles para extranjeros y centros laborales y revolucionarios. En la mayoría de los casos, los que tienen acceso solo pueden navegar por una censurada intranet de páginas locales. (Ibarz, Cuba: In- ternet o muerte, La Nueva Cuba, 23 de junio de 2006). [FC]

En las fuentes españolas lo que más se utiliza es la definición (en ocasiones, más enciclopédica que lingüística): información directa (explícita):

- De los tipos de abuso englobados en ACE, el que más destaca es el conocido como spamque es un término aplicado a mensajes distribuidos a una gran cantidad de destinatarios de forma indiscriminada... (Universidad Autónoma de Madrid. Abuso en el correo electrónico (ACE). Sin autor, sin fecha). [FE]

- Estas normas están orientadas a facilitar la comunicación y a optimizar el uso de las comunicaciones. A las reglas de comportamiento en Internet se las denomina Netiqueta -apócope de las palabras "Net" (red) y "etiqueta"aunque también se las denomina Redtiqueta, Netiquette, etc. (Universidad Autónoma de Madrid, Netiqueta, sin autor, sin fecha). [FE]

Sin embargo, definiciones más actualizadas del $\boldsymbol{e}$-Book, siguen utilizando el término "book" para incurrir en estas imprecisiones apuntadas, y así encontramos entre las más difundidas,

Un $\boldsymbol{e}$-Book o libro electrónico es un libro o publicación digitalizada que ha sido confeccionada para ser comercializada en Internet, por lo que su tamaño, estructura y diseño han debido ser tratados correctamente para que su visualización, tiempo de descarga y posibilidades de utilización sean los adecuados" (Larrañaga y López. El eBook: aspectos culturales y socioeconómicos del sistema editorial online. Documentación de las Ciencias de la Información, 2005, vol. 28). [FE]

Lo mismo ocurre con Guatemala:

- La brecha digital es un término que surgió en la década de 1990 y que se refiere a la diferencia que existe entre los países y sus comunidades en relación al acceso y aprovechamiento de las nuevas Tecnologías de la Información y la Comunicación, TICs, para lograr mejores condiciones de vida. Otros la definen, simple- 
mente, como la diferencia entre quienes están "conectados" y "desconectados". El término se acunó durante la administración del presidente estadounidense Bill Clinton y se origina del inglés digital divide. La frase se le atribuye a Simon Moores, quien con esto se refería a la fractura que podría producirse en los Estados Unidos entre los diferentes territorios, razas, etnias, clases y géneros, si no se invertía en infraestructura y educación. (Martínez, Revista D, Semanario de Prensa Libre, Separados por un clic, 2006, $\mathrm{N}^{\circ}$ 108). [FG]

- También existen virus mandados por los propios spammers que pueden convertir su computadora personal en un zombie, esto es, en una terminal que, sin que usted lo sepa, se dedique a recopilar nuevas direcciones y a mandar más spams, hasta el punto de que puede llegar a recibir mensajes en los que el remitente sea usted mismo. (Gil Flores, Revista D, Semanario de Prensa Libre, iSpamtelos!, 2006, $\mathrm{N}^{\circ} 84$ ). [FG]

- Dos años antes, en 2001, se publicó en Inglaterra una nota de prensa que hablaba de la cibercondría, para describir a la conducta de personas que se dejan guiar por tratamientos publicados en páginas web, y que por lo general no buscan ayuda profesional, o creen tener un diagnóstico incorrecto. (Roldán, Revista D, Semanario de Prensa Libre, Doctor Internet, 2006, No 119). [FG]

- ¿La publicidad sobre destinos turísticos paradisíacos inunda su bandeja de entrada? ¿Suele reenviar esas cadenas de correo destinadas a salvar la selva amazónica o a equilibrar su tantra? Si la respuesta a estas preguntas es afirmativa, es usted víctima del spam. O lo que es lo mismo: todo aquel correo no deseado que, en el mejor de los casos, contiene mensajes publicitarios y, en el peor, un virus informático. (Gil Flores, Revista D, Semanario de Prensa Libre, ;Spamtelos!, 2006, Nº 84). [FG]

El hecho de que en Chile y Cuba no sea frecuente una definición directa y en los otros dos países sí, puede significar que en éstos no existe una intención de dar a conocer el sentido de los términos, es decir, que los textos van dirigidos a un público más especializado; mientras que las fuentes guatemaltecas y españolas se focalizan en un público más general, de ahí que las estrategias de definición sean más explícitas.

Finalmente, señalamos que partimos de la definición de los términos que hacen los autores, pues consideramos que a pesar de hacer parte del campo semántico, también brindan elementos para dilucidar los objetivos e intenciones del enunciador, tales como: dar las características generales de un producto, profundizar en su función o emplear analogías con elementos que pueden ser más comunes para el receptor; ésta última es la más frecuente en el corpus que presentamos. La relación entre estos aspectos semánticos y la pragmática es vital, por cuanto "el divulgador tendrá que seleccionar los nudos conceptuales y adaptarlos, contextualizarlos, escenificarlos, en función de los factores pragmáticos que confluyen en la nueva situación comunicativa" (Mapelli, 2003, en línea). De ahí que el concepto de divulgación esté ligado a los procedimientos semánticos que se empleen para dar a conocer un determinado término. Así, en lo que hemos presentado se ve claramente una estrategia de divulgación, sobre todo la que tiene que ver con

\footnotetext{
la elección de términos o de otros recursos denominativos para referirse a los conceptos. Su observación nos permite ver hasta qué punto la divulgación prefiere utilizar la precisa terminología científico-técnica o bien otras denominaciones más comunes, como sinónimos genéricos o algún tipo de paráfrasis (correferencia, definición, forma metalingüística, etc.) (Cassany y Martí, 1998, en línea).
}

De acuerdo con esto, en los ejemplos presentados es claro un alto grado de contextualización; así, según Cassany y Martí (1998), con el fin de acercar términos y conceptos al público no especialista, la contextualización como estrategia discursiva se entiende como una "construcción previa de un marco de referencia en el que el lector pueda situar dicho concepto cuando aparezca" (Cassany y Martí, 1998, en línea). 
Desde esta óptica, se concibe al redactor científico como un mediador; de ahí nace la necesidad de establecer una relación dialéctica entre el divulgador y sus lectores, basada en principios de cooperación y relevancia, para así lograr el fin último de todo texto: una comunicación fluida y sin equívocos. Los ejemplos que hemos presentado en este trabajo no son precisamente un modelo de comunicación afortunada, con un agravante: algunas revistas universitarias cumplen una función más divulgadora del léxico de la Internet y la informática que la misma prensa digital de los países seleccionados.

\section{Conclusiones}

- Pese a que el léxico de la informática y la Internet posee ciertas características comunes con las otras lenguas de especialidad, también son evidentes algunos aspectos que lo singularizan y que justifican investigaciones al respecto, como los elementos pragmáticos que se pueden evidenciar en los textos divulgativos que presentan este tipo de léxico.

- La principal diferencia entre los dos tipos de fuentes consultadas (periódicos digitales y páginas universitarias), desde el aspecto

\section{Bibliografía}

Belda, J. (2000). Estudio morfológico contrastivo Inglés-español sobre terminología de la informática y de Internet. Alicante, España: Universidad de Alicante, Tesis doctoral. Recuperado el 30 de abril de 2008, de http:// rua.ua.es/dspace/bitstream/10045/3252/1/Belda\%20 Medina\%2c\%20Jos\%c3\%a9\%20Ram\%c3\%b3n.pdf

Cabré, M. (2002). Terminología y lingüística: La teoría de las puertas. Barcelona, España: Universidad Pompeu Fabra (España). Recuperado el 11 de mayo de 2008, de http://elies.rediris.es/elies16/Cabre.html

Calsamiglia, H. et al. (2001). Análisis discursivo de la divulgación científica. Lengua, Discurso, Texto. I Simposio Internacional de Análisis del Discurso (pp. 2640-2646). Madrid, España: Visor Libros. Recupe- pragmático, tiene que ver con que en las revistas universitarias y en los textos académicos (como las tesis doctorales) se busca, en un alto porcentaje de los casos, aclarar el sentido del término empleado -entendiendo esto como una estrategia de divulgación-, elemento que no es primordial en la prensa digital.

- Aunque abogamos por la existencia de un léxico particular en el ámbito de la Internet y la informática, eso no quiere decir que todas las palabras que conforman dicho léxico sean plenamente términos, tal como se puede observar en los siguientes ejemplos: equipo, Internet, comunidad virtual, brecha digital... entre muchos otros que tienen una amplia difusión no sólo en el campo que acá nos ocupa.

- Para lograr un panorama general acerca del léxico de la Internet y la informática en español es necesario recurrir a diversas fuentes de todos los países de habla hispana; sólo así es posible realizar un diagnóstico certero de esta parcela léxica. Es este el reto: abogar por un trabajo práctico que conlleve a propuestas sólidas en pos de un mejor conocimiento y tratamiento de este léxico en español.h rado mayo 11, 2008 de http://www.upf.edu/pdi/dtf/ daniel_cassany/analies2.htm

Calsamiglia, H. (1997). Divulgar: itinerarios discursivos del saber. Quark (No. 7), 9-18. Barcelona, España: Observatorio de la Comunicación Científica. Recuperado abril 30, 2008 de http://www.prbb.org/ quark/7/estrella.htm

Cassany, D. y Martí, J. (1998). Estrategias divulgativas del concepto prión. Quark (No. 12) (julio-septiembre de 1998), 58-66. Barcelona, España: Observatorio de la Comunicación Científica. Recuperado mayo 11, 2008 de http://www.prbb.org/quark/12/012058.htm

Clavería, G., Morales, C. y Torruella, J. (2001). La terminología informática en español. En M. Bargalló, 
E. Forgas, C. Garriga, A. Rubio y J. Schnitzer (eds.), Las lenguas de especialidad y su didáctica (pp. 91102). Tarragona, España: Universitat Rovira i Virgili. Universitat Autònoma de Barcelona: Seminario de Filología e Informática. Recuperado abril 30, 2008 de http://seneca.uab.es/neolcyt/Estudios/pdf/claveria.pdf

Cruz, M. (1999). Espan-1, un foro de debate en Internet sobre la lengua española. Estudios de Lingüística del Español, Vol. I. Recuperado el 30 de abril de 2008, de http://elies.rediris.es/elies1/64.htm

García, J. (2001). En los límites de la especialidad: los textos de divulgación científica. En M. Bargalló, E. Forgas, C. Garriga, A. Rubio y J. Schnitzer (eds.),
Las lenguas de especialidad y su didáctica (pp. 157168). Tarragona, España: Universitat Rovira i Virgili. Recuperado abril 30, 2008 de http://seneca.uab.es/ neolcyt/Estudios/pdf/Palacios.pdf

Gutiérrez, B. (2005). El lenguaje de las ciencias. Madrid, España: Gredos.

Mapelli, G. (2003). La difusión de la terminología científica en la prensa. Recuperado el 12 de junio de 2008, de http://cvc.cervantes.es/obref/ciefe/pdf/02/cvc_ciefe_02_0012.pdf.

Vaquero, A. (1997). El uso de la palabra ordenador. Recuperado el 10 junio de 2008, de http://www.elmundo.es/su-ordenador/SORnumeros/97/SOR066/ SOR066tribuna.html 